Research Article

\title{
Study the Effects of Carbon Nanotubes and Graphene Oxide Combinations on the Mechanical Properties and Flame Retardance of Epoxy Nanocomposites
}

\author{
Tuan Anh Nguyen (iD and Thi Thu Trang Bui $(1)$ \\ Faculty of Chemical Technology, Hanoi University of Industry (HaUI), No. 298, Cau Dien Street, Bac Tu Liem District, \\ Hanoi, Vietnam \\ Correspondence should be addressed to Tuan Anh Nguyen; anhnt@haui.edu.vn
}

Received 10 May 2021; Revised 29 October 2021; Accepted 30 November 2021; Published 27 December 2021

Academic Editor: Dillip K. Panda

Copyright (C) 2021 Tuan Anh Nguyen and Thi Thu Trang Bui. This is an open access article distributed under the Creative Commons Attribution License, which permits unrestricted use, distribution, and reproduction in any medium, provided the original work is properly cited.

\begin{abstract}
Carbon-based fillers have attracted a lot of interest in polymer composites because of their ability to alter beneficial properties at low filler concentrations, good surface bonding with polymers, availability in different forms, etc. Carbon-based materials (such as fullerene, CNTs, graphene, and graphite) have been studied as fillers with enhanced fire resistance to epoxy resins. In order to reduce the flammability and improve the thermal stability of epoxy resin-based nanocomposite materials, which can be achieved by a simultaneous combination of graphene oxide and multiwall carbon nanotubes, the graphite oxide (GO) epoxy nanomaterial was developed by $1 \%$ wt.\% GO combined with 0.02 wand 0.04 wt.\% MWCNT. The homogeneous dispersion of GO and MWCNTs in epoxy resins is supported by ultrasonic vibrations. The results showed that when nanocomposite materials were present at the same time MWCNTs and GO, their mechanical properties and fire resistance were significantly improved. Nanomaterials are characterized by FT-IR spectroscopy and SEM imaging, mechanical strength, and flame retardant properties (LOI, UL94).
\end{abstract}

\section{Introduction}

Graphene oxide (GO) composites are carbon-based materials with excellent performance and low cost. They are applicable in a wide range of civil, mechanical, and aerospace applications. GO material is used in polymer mixture systems as filler to improve mechanical properties of polymer materials. Graphene oxide significantly enhances the durability of composites while it clearly does not decrease the strength of composites [1]. When 0.5 percent by mass or 1.5 percent by mass is added, the mechanical properties of epoxy composite materials improve. GO/epoxy composites will perform very well in applications in the electronics, aerospace, and automotive industries $[2,3]$. In addition, when a small fraction of graphene oxide (GO) was incorporated into epoxy resin (EP), the results showed that GO increased fire resistance, with a limited oxygen index of $24.5 \%$, and resistance tests fire to other standards. The bar- rier effects of GO and the limited mobility of polymer chains are important factors in increasing thermal stability and reducing dangerous carbon monoxide generation during combustion [4]. Guo et al. were also investigated when adding 2 wt.\% GO to epoxy resin, resulting in a 50\% and $19.6 \%$ increase in the learning mode and regeneration module of $\mathrm{GO} / \mathrm{ER}$ material synthesis [5]. In order to improve the synergistic effect of GO/MWCNTs in epoxy resin, a number of research projects have been conducted to modify the surface of MWCNTs to increase compatibility. Fabricated materials show a marked improvement in mechanical properties $[6,7]$. Ultrasound is an appropriate method to disperse GO/MWCNTs into epoxy resins, studies have shown that when adding 0.3 or $0.5 \mathrm{wt} . \% \mathrm{GO}$, and the mechanical properties of nanocomposites are significantly enhanced by the addition of GO $[8,9]$. Bahrami et al. fabricated nanocomposite specimens with $0.02,0.04,0.06,0.08$, and 0.1 wt.\% MWCNTs combined with $1 \%$ mass RGO (oxidized 
GO). The results showed that the mechanical properties could be significantly changed by adding two different nanoparticles simultaneously [10]. Liu et al. used acetone as a solvent to disperse GO/MWCNTs into epoxy. Carbon nanotubes were first dispersed in a solution of acetone, then the epoxy resin is dissolved in the acetone solution, and the filler is evenly dispersed in epoxy resin. Mechanical properties, thermal properties, and electrical conductivity properties of synthetic materials preparation by this method have greatly improved [11]. The graphite oxide (GO) polymer nanomaterial was developed at 1,5 , and $10 \%$ by weight of GO using polycarbonate (PC), acrylonitrile butadiene styrene, and high impact polystyrene for evaluation of fire resistance. This work reveals that GO shows some promise for the fabrication of polymer nanocomposites in which reduced flammability is desired [12]. The phosphaphenanthrene double structure has been successfully grafted onto the surface of graphene oxide (GO), called functionalized graphene oxide (FGO). The introduction of FGO improved poor interface compatibility between the graphene and epoxy matrices. When the FGO content is 3\% by weight, the amount of oxygen is limited the index value reached $30.4 \%$ [13]. Some other works, without modification of GO or MWCNTs, were applied directly to the epoxy resin substrate. Research results indicate that GO is one of the potential flame retardant additives $[14,15]$. Epoxy nanocomposites are fabricated with different GO loads by mixing technical solutions. Several other programs have also demonstrated that the incorporation of a small amount of GO into the epoxy matrix significantly enhances the mechanical properties of epoxy [16-19]. In summary, carbon and its household materials (graphite, MWCNTs, etc.) are potential flame retardant reinforcement in polymer composites, and these reinforcements are attractive alternatives to conventional flame retardants. Carbon-based fillers actively reduce the flammability of polymer composites by (1) protective coal formation layer and (2) absorb free radicals [20-27]. In this work, the combination of MWCNTs and GO affecting the mechanical properties and flame retardation was studied using the high-speed mechanical stirring method combined with the ultrasonic vibration method.

\section{Materials and Methods}

2.1. Materials. Epoxy resin with the trade name epoxy Epikote 240 is supplied from Shell Chemicals (USA). The epoxy group content is $24.6 \%$, and the viscosity is $0.7-1.1 \mathrm{~Pa} . \mathrm{s}$ (25 degrees Celsius). This epoxy resin was chosen because of its low viscosity, making it suitable for dispersing nanoadmixtures. The curing agent for epoxy resin used was diethylene triamine (DETA), supplied by Sigma-Aldrich with MW: $103 \mathrm{~g} \cdot \mathrm{mol}^{-1}$ and specific gravity at $25^{\circ} \mathrm{C}: 0.95 \mathrm{~g} / \mathrm{cm}^{3}$. Multiwalled carbon nanotubes (MWCNTs) were provided by Showa Denko Japan Co., with a diameter of 40 to 45 nanometers and a length of about $3 \mu \mathrm{m}$. Graphene oxide is a gray-brown solid, with a $\mathrm{C}: \mathrm{O}$ ratio of $2: 1$ to $2: 9$, well dispersed in water and many other solvents. GO was synthesized according to Hummers' improved method, and then GO was dispersed in water at a concentration of $5 \mathrm{mg} / \mathrm{mL}$.

\subsection{Methods}

\subsubsection{Sample Preparation}

(i) Sample Preparation by Sonication Mixing: epoxy resin was dried for 1 hour in a $100^{\circ} \mathrm{C}$ vacuum oven to release air. Then, mix with GO by mechanical stirring for 60 minutes at a stirring speed of $3000 \mathrm{rpm}$, continuing to vibrate ultrasound for 6 hours at room temperature. The mixtures are then poured into Teflon coated molds after dehydrating in a vacuum oven for 30 minutes. Samples were prepared at room temperature for 24 hours and after curing at $80^{\circ} \mathrm{C}$ for 3 hours. To stabilize the sample for 7 days, then go to measure the mechanical properties and the flame retardant properties

(ii) Preparation of nanocomposite specimens: epoxy resin was dried for 1 hour in a $100^{\circ} \mathrm{C}$ vacuum oven to release air. Then, mix with $1 \%$ by weight GO combined with $0.02 \mathrm{wt} \%$ and $0.04 \mathrm{wt} \%$ MWCNT by mechanical stirring for 60 minutes at stirring speed of $3000 \mathrm{rpm}$, continuing to vibrate ultrasound for 6 hours at room temperature. The mixtures are then poured into Teflon coated molds after dehydrating in a vacuum oven for 30 minutes. Samples were prepared at room temperature for 24 hours and after curing at $80^{\circ} \mathrm{C}$ for 3 hours. To stabilize the sample for 7 days, then go to measure the mechanical properties and the flame retardant properties

\subsubsection{Analysis}

(i) Limiting oxygen index (LOI) according to JIS K720 standard (Japan): the sample bars used for the test were $150 \times 6.5 \times 3 \mathrm{~mm}^{3}$

(ii) The horizontal burning tests (UL-94HB): standard bar specimens are $125 \pm 5 \mathrm{~mm}$ long by $13.0 \pm 0.5$ $\mathrm{mm}$ wide and provided in the minimum thickness and $3.0(-0.0+0.2) \mathrm{mm}$ thick (ASTM D635-12)

(iii) Vertical burning test: UL $94 \mathrm{~V}$, the standard bar samples shall be $125 \pm 5 \mathrm{~mm}$ long $\times 13.0 \pm 0.5 \mathrm{~mm}$ wide and supplied in the minimum and maximum thicknesses. The maximum thickness does not exceed $13 \mathrm{~mm}$ (ASTM D635-12)

(iv) The UL 94 flame retardant and oxygen limit tests are conducted at the Polymer Materials Research Center-Hanoi University of Technology, Vietnam

(v) The morphology of the samples was carried out by scanning electron microscope (SEM, S4800, Japan)

(vi) Fourier transform infrared spectrum (FTIR) is recorded using FTS 2000 FTIR (Varian) using $\mathrm{KBr}$ tablets that are created by compressing $\mathrm{KBr}$ powder mixed with a small amount of sample GO

(vii) Tensile strength, flexural strength, and compressive strength were measured on an INSTRON 


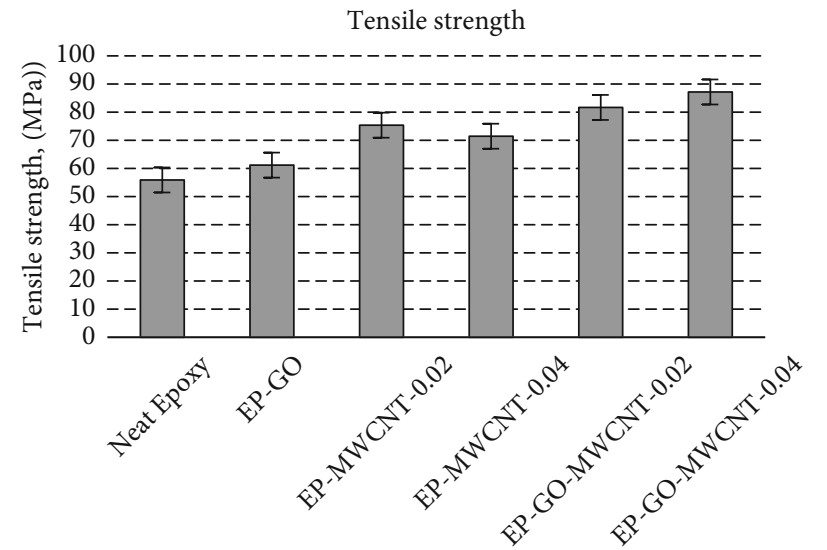

Material



Material

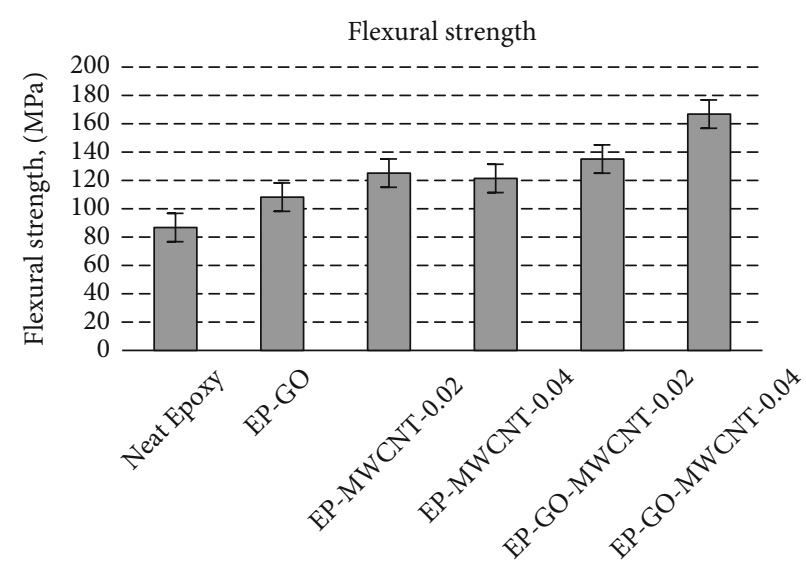

Material

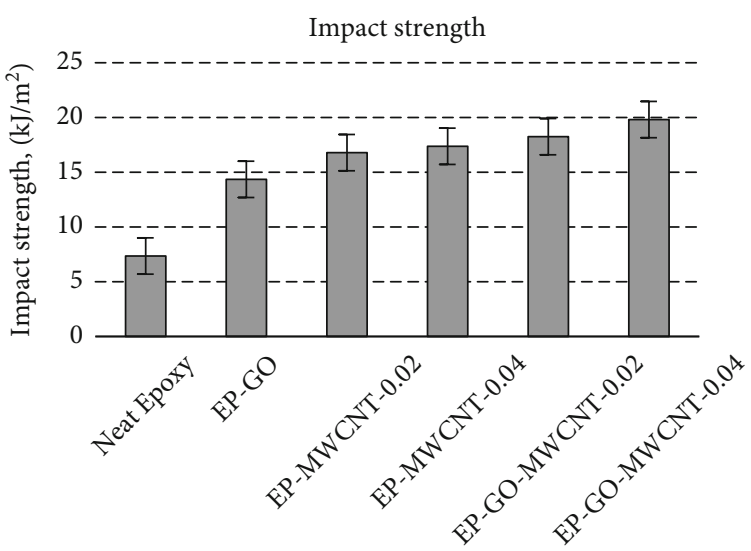

Material

FIGURE 1: Mechanical properties of epoxy composite materials (EP-GO: 1 wt.\% GO; EP-MWCNTs-0.02: 0.02 wt.\% MWCNTs; EPMWCNTs-0.04: 0.04 wt.\% MWCNTs; EP-GO-MWCNTs-0.02: 1 wt.\% GO/0.02 wt.\% MWCNTs; EP-GO-MWCNTs-0.04: 1 wt.\% GO/ 0.04 wt.\% MWCNTs).

5582-100 kN machine (USA) with a tensile speed of $5 \mathrm{~mm} / \mathrm{min}$, a temperature of $25^{\circ} \mathrm{C}$, and a humidity of $75 \%$, according to ISO $178-1993$ standards

(viii) Izod impact strength was measured on a Tinius Olsen machine (USA), according to ASTM D265 standard, conducted at the Research Center for Polymer Materials, Hanoi University of Science and Technology

\section{Results and Discussion}

3.1. Mechanical Properties. Figure 1 shows the mechanical properties of epoxy resin-based composite materials, $1 \mathrm{wt} . \%$ GO combined with 0.02 wt.\% and 0.04 wt.\% MWCNTs, respectively. To study the effect of the combination of GO and MWCNTs on the material's mechanical properties, we compared and discussed materials: neat epoxy, EP-GO, EP-MWCNTs, and EP-GO-MWCNTs. From Figure 1, it is confirmed that GO and MWCNTs can enhance the mechanical properties of nanocomposites based on epoxy resins. From Figure 1, it is confirmed that GO and MWCNTs can enhance the mechanical properties of nanocomposites based on epoxy resins. The tensile strength, flexural strength, compressive strength, and impact strength all tended to increase when 1 wt. \% GO, 0.02 wt. \%, and 0.04 wt. \% MWCNTs were added, especially in the sample when combining the two additives above. In the combination of 1 wt. \% GO with $0.04 \mathrm{wt}$, \% MWCNT mechanical properties reach the best value (tensile strength: $87.17 \mathrm{MPa}$, flexural strength: 166.81 MPa, compressive strength: $190.68 \mathrm{MPa}$, and impact resistance: $19.68 \mathrm{KJ} / \mathrm{m}^{2}$ ).

Medhekar et al. 2010 recommend that GO is superior. These can be good indicators for better crosslinking, uniform distribution, and good interface interaction through covalent bonding between GO and matrix [28]. Good interface bonding facilitates the efficiency of force transfer resulting in increased material resistance [29]. Thus, the aforementioned properties of hybrid nanocomposites with a suitable filler ratio have higher improvements than those made in the individual mode [30]. Hybrid nanocomposites with total content of $1 \%$ by weight GO and $0.04 \%$ by weight of MWCNTs showed the best results in the study.

3.2. Fire Retardant Property. The effects of GO and MWCNTs on LOI values are shown in Figure 2. 

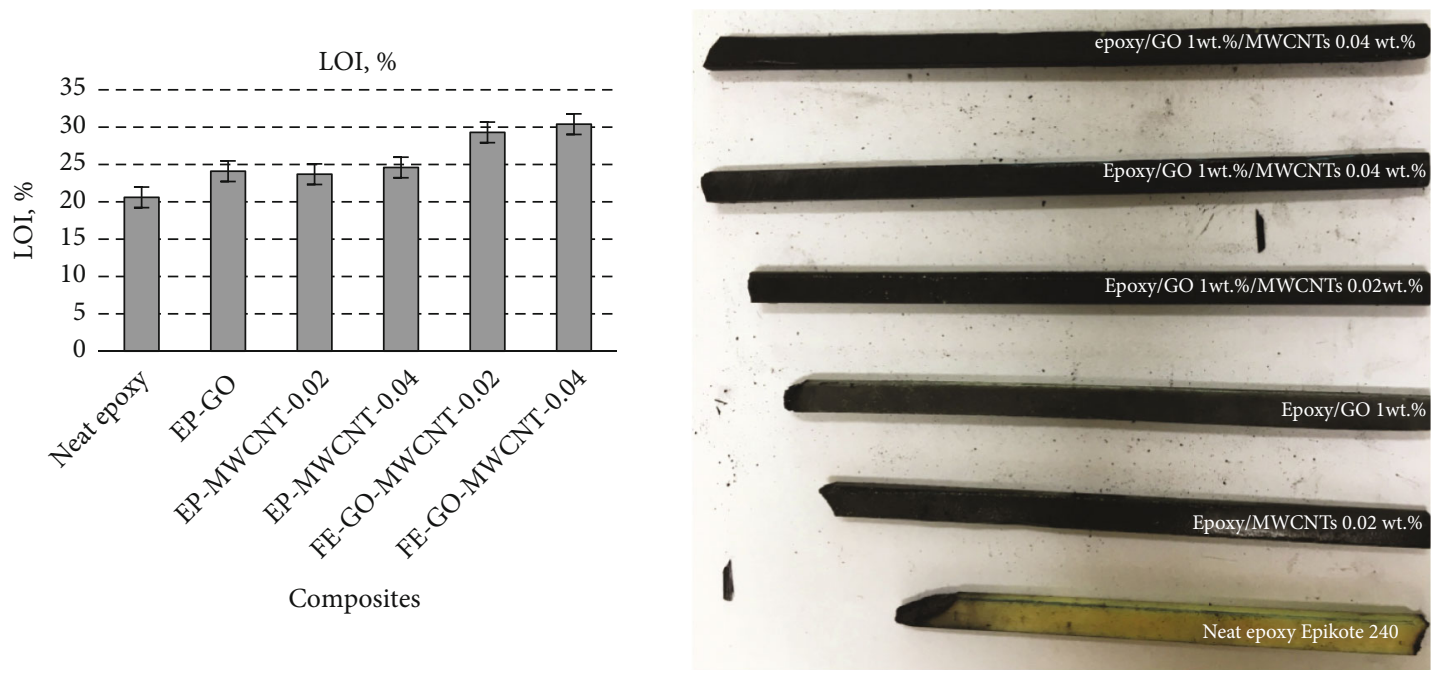

Figure 2: LOI values of epoxy composite (EP-GO: 1 wt.\% GO; EP-MWCNTs-0.02: 0.02 wt.\% MWCNTs; EP-MWCNTs-0.04: 0.04 wt.\% MWCNTs; EP-GO-MWCNTs-0.02: 1 wt.\% GO/0.02 wt.\% MWCNTs; EP-GO-MWCNTs-0.04: 1 wt.\% GO/0.04 wt.\% MWCNTs).

TABLE 1: Combustion parameters of epoxy composites.

\begin{tabular}{lcccc}
\hline Samples & & & UL-94 V & \\
Neat epoxy & $t_{1}(\mathrm{~s})$ & $t_{2}(\mathrm{~s})$ & & Burning grade \\
$\quad$ & & & - & Dripping \\
EP-GO & $>30$ & - & - & Yes \\
EP-MWCNTs-0.02 & $>30$ & - & - & Yes \\
EP-MWCNTs-0.04 & $>30$ & 17 & N-1 & No \\
EP-GO-MWCNTs-0.02 & 21 & 16 & V-1 \\
EP-GO-MWCNTs-0.04 & 18 & & & No \\
\hline
\end{tabular}

When the amount was added to 1 wt. \% GO, the oxygen index of the material reached $24.1 \%$. When combining (hybrid between GO and MWCNTs) 1wt. \% with 0.02 wt. \% MWCNTs, the oxygen index is $29.3 \%$ and when MWCNTs increase to $0.04 \mathrm{wt}$. \%, the oxygen index is $30.4 \%$. It was found that GO could effectively improve the flame retardant performance of epoxy composite materials, and the ability increased further with MWCNTs included.

The UL-94 tests (Table 1) showed material on the basis of combining $1 \mathrm{wt} . \% \quad \mathrm{GO}$ with $0.02 \mathrm{wt} . \%, \quad 0.04 \mathrm{wt} . \%$ MWCNTs reached at V1, and no minor phenomena drop after the flame is extinguished. With the assessment results of LOI index, UL-94 V, GO is one of the highly effective green flame retardants when combined with nanoadditive MWCNTs. When the GO content was $1 \%$ by weight combined with $0.04 \%$ by weight of MWCNT, the limiting oxygen index value reached $30.4 \%$. The effectiveness of increased fire resistance and smoke suppression is mainly due to the formation of the physical barrier and the compressibility of the developed GO/MWCNT composite coal layers, which act as an effective barrier layer. The increased fire resistance and thermal stability of the coal layers stems from the effect of the synergistic inclusion between GO and MWCNT.
GO and MWCNts work together to form an excellent carbon layer with high strength and thermal stability. It prevents heat penetration and volatile metamorphic products and further slows down the rate of heat release, thus protecting the underlying matrix from fire during combustion [13].

The significant increase in flame retardants is due to the formation of excellent coal layers with high strength and thermal stability of GO and MWCNTs. The developed coal layers can slow heat penetration and volatile decomposing materials during combustion, thereby limiting ignition and protecting the underlying polymer from flames. Such a result leads to the formation of a denser carbon layer. The reduced EP flammability is related to the development of coal formation and the creation of GO's "winding line" and the effect of the barrier during ignition. This work provides a clean and simple solution for the production of active graphene-based flame retardants to enhance EP resin flame retardants compared to halogenated or nonhalogen composites that release acidic gases at high temperatures or deteriorate the mechanical properties of composites. One of the important novelties achieved in this research is the discovery of flame retardants that retain the mechanical properties of the composite matrix or do not release toxic gases at high temperatures [31]. 



Figure 3: SEM images of GO/epoxy composite (1 wt. \% GO) at different resolutions.

The flame retardant effect between MWCNTs and GO promotes the formation of dense additional layers of coal and improves the thermal oxidation resistance of graphene and MWCNTs. A layer of highly thermally stable coal, consisting of graphene sheets combined with MWCNTs nanoparticle, slows heat penetration and release of volatile metamorphic products [32].

3.3. Morphology. SEM has been used in this study to investigate the morphology of EP-based composites: EP-GO and EP-GO-MWCNTS.

Figure 3 shows the fracture surface morphology of the material GO/epoxy resin composite material. Figure 3 shows that the graphene oxide has dispersed into layers and therefore, the substrate is compatible with the epoxy-GO interface. When the system is loaded, GO evenly dispersed within the composite material can bear the load and prevent and stop developing cracks. In the form of fracture, impact and rough fracture surface, and damaged surface, more energy consumption is greater. It proves that the appearance of GO in the material has a great impact on the formation of cracks and the restriction of defects. Materials can extend their resistance to factors such as mechanical forces. Thus, we can see that the addition of structure GO to EP has reduced the number of cracks of the material under the impact (see SEM image, Figure 3).

Figure 4 shows that MWCNTs are well dispersed in the epoxy matrix. These SEM images clearly illustrate that the MWCNT particles were well dispersed, and there was no evidence of MWCNT aggregation. These nanotubes also appear to be encapsulated with a polymer epoxy matrix. On the other hand, graphene oxide sheets can be seen in
Figure 4 dispersed in the epoxy matrix according to layers. The SEM image also showed the fracture surface of the material revealing that the GO scale did not aggregate into a dense region. The GO fragments, several micrometers in size, were found protruding from the polymer matrix and indicated by the white arrows. The presence of nanofillers (MWCNTs) and GO in the epoxy resin substrate not only improved the mechanical properties but also changed the fracture pattern of the nanocomposites. This can be explained by SEM imaging of the fracture surfaces for pure epoxy and nanomaterials as illustrated in Figure 5. The fracture surface of pure epoxy is shown in Figure 5(c), which has a uniform pattern characterized by smooth and parallel lines exposing cracks in the fracture surface and a brittle fracture mechanism $[16,33]$. This shows that during the load, cracks develop without obstacles along their direction. As Figures 5(a) and 5(b) shows, the disorder appears more at the fracture surface due to the presence of GO. This is thought to be due to crack development due to the properties of the epoxy resin brittle. Because epoxy resin has a brittle weakness, when the force exerts the epoxy monolithic areas, cracks will appear.

When the crack develops and spreads met with GO and nanoparticles (MWCNTs) (Figure 5(d)), the crack changes its trajectory, and the direction is skewed. Consequently, new lines, new fracture surfaces, and new branch cracks are created on the fracture surface. The fracture surface in this case has irregular faces as illustrated in Figure 5. Obviously, the creation of new branching and fracture surfaces due to the containment of GO and of MWCNTs (Figure 5(d)) requires additional energy to be able to model the fracture or pull prolongs the application of the force. The 

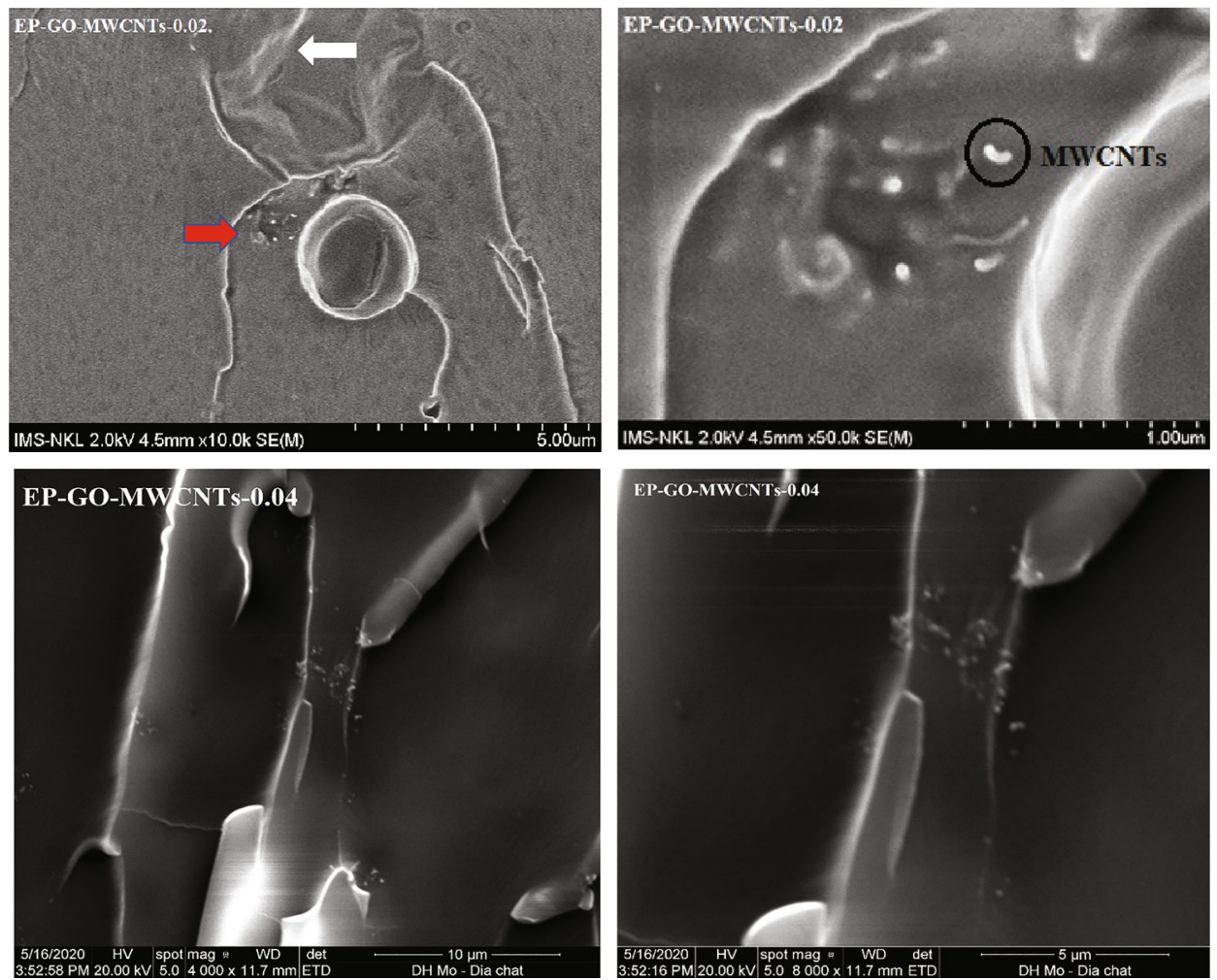

Figure 4: SEM images of GO/MWCNTs/epoxy composite: EP-GO-MWCNTs-0.02 and EP-GO-MWCNTs-0.04.



(a) : GO/epoxy composite (1 wt.\% GO)



(c) : epoxy/GO/1 wt\%/MWCNTs/0.04 wt

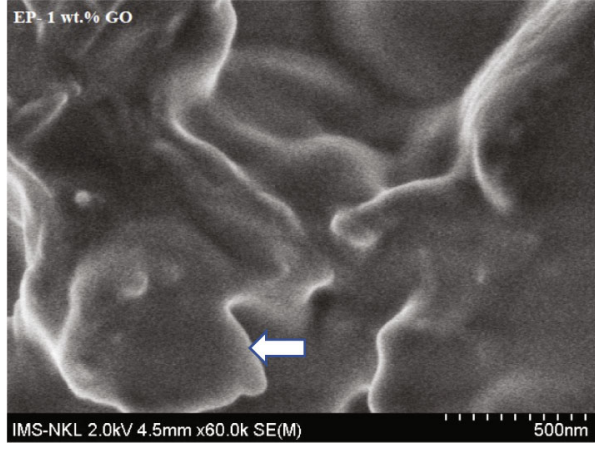

(b) : GO/epoxy composite (1 wt.\% GO)



(d) : GO/epoxy(1 wt.\% GO)/MWCNTs (0.04 wt.\%)

Figure 5: SEM images of GO/epoxy composite (1 wt.\% GO), GO(1 wt.\%)/MWCNTs (0.04 wt.\%)/epoxy composite, and neat epoxy. 
IR



(A)

(C)

(B)

(D)

Figure 6: Results of infrared spectroscopy measurements: (a)-EP + GO (1\%) + C (0.04\%), (b)-EP + GO (1\%) + C (0.02\%), (c) EP + GO (1\%), and (d)-EP (epoxy Epikote 240) (C: MWCNTs: multiwalled carbon nanotubes).

uniform distribution of fracture patterns observed in the fracture surface shown in Figure 5 is evidence of the uniform dispersion of the filler in the epoxy resin substrate $[16,33]$. The improvements are due to the existence of GO nanosheets and their contribution to stiffness enhancement, acting as a barrier to prevent crack growth and deflecting them. As shown, the smooth fracture surface of pure epoxy is transformed into a rough surface. This occurs due to the existence of GO sheets as reinforcing material in epoxy as well as their contribution to hardness enhancement, acting as an obstacle to prevent crack growth [34-37].

3.4. Results of Infrared Spectroscopy (IR) Measurement. Figure 6 shows the infrared (IR) spectrum of epoxy resin samples with absorption frequencies characteristic for covalent oscillation of the group: $\mathrm{OH}$ and $\mathrm{CH}$ of the $\mathrm{CH}_{2}$ group and of the aromatic ring, $\mathrm{C}=\mathrm{C}$ of the ring aromatic, $\mathrm{CO}$ - in ether, and CO- in the oxirane ring are $3507.92 \mathrm{~cm}^{-1}$, $3056.89 \mathrm{~cm}^{-1}, \quad 2925.01 \mathrm{~cm}^{-1}, \quad 2854.49 \mathrm{~cm}^{-1}, \quad 1607.34 \mathrm{~cm}^{-1}$, $1505.43 \mathrm{~cm}^{-1}, 1454.54 \mathrm{~cm}^{-1}, 1035.40 \mathrm{~cm}^{-1}, 915.15 \mathrm{~cm}^{-1}$, and $756.41 \mathrm{~cm}^{-1}$, respectively.

Observed in Figures 3(b)-3(d), we can see that the valence of the $\mathrm{O}-\mathrm{H}$ group from $3507.92 \mathrm{~cm}^{-1}$ was moved down to $3363.91 \mathrm{~cm}^{-1}, 3399.02 \mathrm{~cm}^{-1}$, and $3412.49 \mathrm{~cm}^{-1}$. The legs of absorbing streaks in turn tend to expand. - $\mathrm{C}-\mathrm{H}$ valence fluctuation of the $\mathrm{CH}_{2}$ group and leg aromatic ring of absorption stripe were narrow and shorten. There is a loss of covalent oscillation frequency of the $\mathrm{C}-\mathrm{O}$ group in the oxirane ring compared to Figure 3(a) at frequency $915.15 \mathrm{~cm}^{-1}$ due to curing reaction. The research results are consistent with the work published by Tuan Anh Nguyen et al. [37].

\section{Conclusions}

The results of this study showed that the combination of 1 wt.\% GO and 0.02 wt.\% or 0.04 wt.\% MWCNTs in the fabrication of epoxy composite materials improved mechanical properties and flame retardation. Obviously, the combination of GO and MWCNTs at the appropriate percentage of mass has brought into play an effective synergy in the fabrication of composite materials with high mechanical properties and good flame retardant properties. This research result opens up many directions for work and study in the future. In addition, SEM showed that GO and MWCNTs were well dispersed throughout the material. This work reveals that GO shows some promise for the fabrication of polymer nanomaterials in which reduced flammability is desired, especially when combined with the nanoadditive MWCNTs.

\section{Data Availability}

The experimental data used to support the findings of this study are included within the article.

\section{Conflicts of Interest}

The authors declare that there is no conflict of interest regarding the publication of this paper.

\section{Acknowledgments}

The authors wish to thank the Faculty of Chemical Technology, Hanoi University of Industry, Vietnam, for funding this work. 


\section{References}

[1] A. Kausar, I. Rafique, Z. Anwar, and B. Muhammad, "Perspectives of epoxy/graphene oxide composite: significant features and technical applications," Polymer-Plastics Technology and Engineering, vol. 2015, pp. 1525-6111, 2015.

[2] S. I. Abdullah and M. N. M. Ansari, "Mechanical properties of graphene oxide (GO)/epoxy composites," HBRC Journal, vol. 11, no. 2, pp. 151-156, 2014.

[3] J. Tang, H. Zhou, Y. Liang, X. Shi, X. Yang, and J. Zhang, "Properties of graphene oxide/epoxy resin composites," Journal of Nanomaterials, vol. 2014, Article ID 696859, 5 pages, 2014.

[4] M. Sabet, H. Soleimani, S. Hosseini, and E. Mohammadian, "Impact of graphene oxide on epoxy resin characteristics," High Performance Polymers, vol. 33, no. 2, pp. 165-175, 2021.

[5] W. Xiao, Y. Liua, and S. Guo, "Composites of graphene oxide and epoxy resin assuming uniform 3D graphene oxide network structure," RSC Adv., vol. 90, pp. 86904-86908, 2016.

[6] V. Patil, R. V. Dennis, T. K. Rout, S. Banerjee, and G. D. Yadav, "Graphene oxide and functionalized multi walled carbon nanotubes as epoxy curing agents: a novel synthetic approach to nanocomposites containing active nanostructured fillers," RSC Advances, vol. 4, no. 90, pp. 49264-49272, 2014.

[7] M. B. Moraes, L. Cividanes, and G. Thim, "Synthesis of graphene oxide and functionalized CNT nanocomposites based on epoxy resin," Journal of Aerospace Technology and Management, vol. 10, pp. 1-10, 2018.

[8] Y. Arooj and Z. Yan, "Electromagnetic wave Absorbing Characteristics of Graphene-oxide dispersed Carbon nanotubes/ Epoxy Composites," in Proceedings of 2015 12th International Bhurban Conference on Applied Sciences \& Technology (IBCAST), Islamabad, Pakistan, 2015.

[9] N. Norhakim, S. H. J. Ahmad, C. H. Chia, and N. M. Huang, "Mechanical and thermal properties of graphene oxide filled epoxy nanocomposites," Sains Malaysiana, vol. 43, no. 4, pp. 603-609, 2014.

[10] M. A. Bahrami, M. Heshmati, and S. Feli, "A study on the synergistic influence of reduced graphene oxide and MWCNTs on the mechanical properties of epoxy nanocomposite," Amirkabir Journal of Mechanical Engineering, vol. 53, no. 6, pp. 13-13, 2021.

[11] J. Liu and L. An, "Synthesis and properties of graphene/carbon nanotube/epoxy resin composites," Chemical Engineering Transactions, vol. 71, pp. 1-6, 2018.

[12] A. L. Higginbotham, J. R. Lomeda, A. B. Morgan, and J. M. Tour, "Graphite oxide flame-retardant polymer Nanocomposites," ACS Applied Materials \& Interfaces, vol. 1, no. 10, pp. 2256-2261, 2009.

[13] W. Wenqian, X. Yiting, W. Haiyang et al., "Synthesis of modified graphene oxide and its improvement on flame retardancy of epoxy resin," Journal of Applied Polymer Science, vol. 2019, pp. 1-11, 2019.

[14] Y. R. Lee, S. C. Kim, H.-i. Lee et al., "Graphite oxides as effective fire retardants of epoxy resin," Macromolecular Research, vol. 19, no. 1, pp. 66-71, 2011.

[15] A. G. Bannov, O. B. Nazarenko, E. A. Maksimovskii, M. V. Popov, and I. S. Berdyugina, "Thermal behavior and flammability of epoxy composites based on multi-walled carbon nanotubes and expanded graphite: a comparative study," Applied Sciences, vol. 10, no. 19, p. 6928, 2020.
[16] G. H. Majzoobi, S. H. A. Nejad, and S. A. R. Sabet, "Role of graphene oxide and sonication time on mechanical properties of epoxy nanocomposites at high strain rate," Materials Research Express, vol. 6, no. 6, p. 065063, 2019.

[17] D. Galpaya, M. Wang, G. George, N. Motta, E. Waclawik, and C. Yan, "Preparation of graphene oxide/epoxy nanocomposites with significantly improved mechanical properties," Journal of Applied Physics, vol. 116, no. 5, p. 053518, 2014.

[18] G. V. Seretis, I. D. Theodorakopoulos, D. E. Manolakos, and C. G. Provatidis, "Effect of sonication on the mechanical response of graphene nanoplatelets/glass fabric/epoxy laminated nanocomposites," Composites, Part B: Engineering, vol. 147, pp. 33-41, 2018.

[19] J.-L. Phua, P.-L. Teh, S. A. Ghani, and C.-K. Yeoh, "Effect of Heat Assisted Bath Sonication on the Mechanical and Thermal Deformation Behaviours of Graphene Nanoplatelets Filled Epoxy Polymer Composites," International Journal of Polymer Science, vol. 2016, Article ID 9767183, 8 pages, 2016.

[20] K. Babu, G. Rendén, R. Afriyie Mensah et al., "A review on the flammability properties of carbon-based polymeric composites: state-of-the-art and future trends," Polymers, vol. 12, no. 7, pp. 1518-1519, 2020.

[21] D. G. Papageorgiou, I. A. Kinloch, and R. J. Young, "Mechanical properties of graphene and graphene-based nanocomposites," Progress in Materials Science, vol. 90, no. 2017, pp. 75127, 2017.

[22] T. A. Nguyen, Q. T. Nguyen, X. C. Nguyen, and V. H. Nguyen, "Study on fire resistance ability and mechanical properties of composites based on Epikote 240 Epoxy Resin and thermoelectric fly ash: an ecofriendly additive," Journal of Chemistry, vol. 2019, Article ID 2635231, 8 pages, 2019.

[23] T. A. Nguyen, "Effects of the amount of fly ash modified by stearic acid compound on mechanical properties, flame retardant ability, and structure of the composites," International Journal of Chemical Engineering, vol. 2020, Article ID 2079189, 6 pages, 2020.

[24] T. A. Nguyen and Q. T. Nguyen, "Study on synergies of fly ash with multiwall carbon nanotubes in manufacturing fire retardant epoxy nanocomposite," Journal of Chemistry, vol. 2020, Article ID 6062128, 9 pages, 2020.

[25] T. A. Nguyen and T. M. H. Pham, "Study on the properties of epoxy composites using fly ash as an additive in the presence of nanoclay: mechanical properties, Flame Retardants, and Dielectric Properties," Journal of Chemistry, vol. 2020, Article ID 8854515, 11 pages, 2020.

[26] T. A. Nguyen, Q. T. Nguyen, and T. P. Bach, "Mechanical properties and flame retardancy of epoxy resin/nanoclay/multiwalled carbon nanotube nanocomposites," Journal of Chemistry, vol. 2019, Article ID 3105205, 9 pages, 2019.

[27] T. A. Nguyen, "Mechanical and flame-retardant properties of nanocomposite based on epoxy resin combined with epoxidized linseed oil, which has the presence of nanoclay and MWCNTs," Journal of Chemistry, vol. 2020, Article ID 2353827, 8 pages, 2020.

[28] N. V. Medhekar, A. Ramasubramaniam, R. S. Ruoff, and Shenoy, "Hydrogen bondnetworks in graphene oxides nanocomposites paper: Structural and mechanical properties," American Chemical Society, vol. 4, pp. 2300-2306, 2010.

[29] T. Glaskova, M. Zarrelli, A. Aniskevich, M. Giordano, L. Trinkler, and B. Berzina, "Quantitative optical analysis of filler dispersion degree in MWCNT-epoxy nanocomposite," 
Composites Science and Technology, vol. 72, no. 4, pp. 477-481, 2012.

[30] Y.-M. Jen, J.-C. Huang, and K.-Y. Zheng, "Synergistic effect of multi-walled carbon nanotubes and graphene nanoplatelets on the monotonic and fatigue properties of uncracked and cracked epoxy composites," Polymers, vol. 12, no. 9, p. 1895, 2020.

[31] M. Sabet, H. Soleimani, S. Hosseini, and E. Mohammadian, "Impact of graphene oxide on epoxy resin characteristics," High Performance Polymers, vol. XX, no. X, pp. 1-11, 2020.

[32] W. Wenqian, X. Yiting, W. Haiyang et al., "Synthesis of modified graphene oxide and its improvement on flame retardancy of epoxy resin," Journal of Applied Polymer Science, vol. 47710, pp. 1-11, 2020.

[33] D. A. Hawkins Jr. and A. Haque, "Fracture toughness of carbon-graphene/epoxy hybrid nanocomposites," Procedia Engineering, vol. 90, pp. 176-181, 2014.

[34] R. Eqra, M. H. Moghim, and N. Eqra, "A study on the mechanical properties of graphene oxide/epoxy nanocomposites," Polymers and Polymer Composites, vol. 29, 9_Supplement, pp. S556-S564, 2021.

[35] B. Wicklein, A. Kocjan, G. Salazar-Alvarez et al., "Thermally insulating and fire-retardant lightweight anisotropic foams based on nanocellulose and graphene oxide," Nature Nanotechnology, vol. 10, no. 3, pp. 277-283, 2015.

[36] J. Keyte, K. Pancholi, and J. Njuguna, "Recent developments in graphene oxide/epoxy carbon fiber-reinforced composites," Frontiers in Materials, vol. 6, p. 224, 2019.

[37] T. A. Nguyen and T. T. T. Bui, "Effects of hybrid graphene oxide with multiwalled carbon nanotubes and nanoclay on the mechanical properties and fire resistance of epoxy nanocomposite," Journal of Nanomaterials, vol. 2021, Article ID 2862426, 7 pages, 2021. 